Article

\title{
Analysis of Selected Mycotoxins in Maize from North-West South Africa Using High Performance Liquid Chromatography (HPLC) and Other Analytical Techniques
}

\author{
Theodora Ijeoma Ekwomadu ${ }^{1,2, * \mathbb{C}}$, Toluwase Adeseye Dada ${ }^{1,2}$, Stephen Abiola Akinola ${ }^{1,2}$, Nancy Nleya ${ }^{1,2}$ \\ and Mulunda Mwanza ${ }^{1,2}$ D \\ 1 Department of Animal Health, Faculty of Natural and Agriculture, Sciences, Northwest University, \\ Private Bag X2046, Mmabatho 2735, South Africa; adedad@gmail.com (T.A.D.); \\ akinolastephen3@gmail.com (S.A.A.); dangwa@gmail.com (N.N.); mulunda.mwanza@nwu.ac.za (M.M.) \\ 2 Food Security and Food Safety Niche Area, Northwest University, Private Bag X2046, Mmabatho 2735, South Africa \\ * Correspondence: 23115394@nwu.ac.za; Tel.: +27-712-235-215
}

\section{check for}

updates

Citation: Ekwomadu, T.I.; Dada, T.A.; Akinola, S.A.; Nleya, N.; Mwanza, M. Analysis of Selected

Mycotoxins in Maize from

North-West South Africa Using High Performance Liquid Chromatography (HPLC) and Other Analytical Techniques. Separations 2021, 8, 143. https://doi.org/10.3390/separations 8090143

Academic Editor: Salvatore Barreca

Received: 10 August 2021

Accepted: 24 August 2021

Published: 3 September 2021

Publisher's Note: MDPI stays neutral with regard to jurisdictional claims in published maps and institutional affiliations.

Copyright: (C) 2021 by the authors Licensee MDPI, Basel, Switzerland. This article is an open access article distributed under the terms and conditions of the Creative Commons Attribution (CC BY) license (https:/ / creativecommons.org/licenses/by/ $4.0 /)$.

\begin{abstract}
Contamination of foods by mycotoxins is linked to various health and economic implications. This study evaluated the incidence of mycotoxins in commercial and small-scale maize and evaluated potential health risks for consumers based on South African and international regulations. The sensitivity/specificity of HPLC over other analytical methods used was also ascertained. In total, 100 maize samples were analyzed using immuno-affinity column for extraction and clean-up, thin layer chromatography (TLC), HPLC, and enzyme linked immunosorbent assay (ELISA) for quantification. Results revealed that fumonisin $B_{1}$ was the most contaminant mycotoxin in both small-scale and commercial samples with incidence rates of $100 \%$ and $98.6 \%$, respectively. Aflatoxins contamination occurred at incidences of $26.7 \%$ in small-scale and $25.0 \%$ in commercial samples. Furthermore, ochratoxin A had high incidence rates of $97.8 \%$ and $93.0 \%$ and ranged from $3.60-19.44 \mu \mathrm{g} / \mathrm{kg}$ and $1.60-9.89 \mu \mathrm{g} / \mathrm{kg}$, respectively, in small-scale and commercial samples, while ZEA occurred in $50 \%$ and $55 \%$ of small-scale and commercial samples, respectively. Results demonstrate that maize, especially from small-scale farmers, may contribute to dietary exposure to mycotoxins. Farmers and consumers should be alerted to the dangers of mycotoxins contamination in maize with resultant health risks. Additionally, HPLC method was also found to be more specific for mycotoxin detection than ELISA.
\end{abstract}

Keywords: maize; mycotoxins; ELISA; immunoaffinity; HPLC; chromatography; North-West; South Africa

\section{Introduction}

Mycotoxins (from "myco" fungus and toxin) are natural, chemically diverse, fungal products that have harmful effects on exposed humans and animals in a variety of ways [1]. They are non-volatile, relatively low molecular weight compounds [1] synthesized mainly by the secondary metabolism of some filamentous fungi [2]. The existence of mycotoxins came into the limelight in 1960, when more than 100,000 turkeys died in the United Kingdom as a result of the Turkey $X$ disease after consuming aflatoxin-contaminated peanut meal [3]. Currently, some 300 to 400 mycotoxins are known, of which, just about a dozen regularly receive attention as threats to human and animal health [2]. These toxins, when ingested by humans and animals through food or feed, respectively, cause health hazards and lead to economic losses [4]. The significance of the health risk due to mycotoxin contamination depends on the toxicological properties of the particular compound (acute, long-term toxicity, mutagenicity, teratogenicity, carcinogenicity) as well as the extent of the exposure, i.e., the level of contamination in both animals and man [5]. However, human exposure to mycotoxins can result from the direct consumption of contaminated agricultural crops or from the consumption of foods derived from animals (milk, meat, and eggs) [6]. 
Maize (Zea mays L.) is one of the major world cereal grains and ranks as the third largest produced grain behind wheat and rice. It serves great purposes of economic significance, as it not only serves as human food and as a feed for livestock but also as an important commodity in international trade [6]. However, maize is susceptible to infestation by many insect pests and fungal development, which most often results in mycotoxin production. Although fumonisins and aflatoxins most often occur in maize, fumonisins were reported to predominate [7-9]. Several disease outbreaks were linked to consumption of contaminated maize, which includes the human oesophageal cancer in the Transkei region of South Africa [10]. Between January and June 2004, acute aflatoxicosis was reported in eastern Kenya, and 125 of 317 cases of acute hepatic failure resulting in death were attributed to consumption of contaminated maize [11]. Thus, maize remains the main source of dietary mycotoxin exposure to both humans and animals, especially in areas where maize serves as a major dietary staple.

The North West province of South Africa is the second major maize producing region in the country after the Free State. In the North West province, as is the case in much of the world, fungal and mycotoxin contamination of maize is of great concern. This is because maize constitutes the major staple food, is produced commercially and on a small scale, is used extensively as livestock feed, and also serves as an export crop [12]. However, several researchers analyzed and quantified mycotoxins in different parts of the country, especially Fusarium toxins contaminating maize grains and other cereals [13-15]. Thus, because of the various factors, including climatic changes that trigger fungal and mycotoxin contamination of crops, threatening food security and food safety, constant monitoring of these mycotoxins is needed to prevent outbreak of mycotoxicosis.

\section{Materials and Methods}

\subsection{Chemicals and Reagents}

All reagents and chemicals used were of analytical grade and were obtained from Merck, Johannesburg, South Africa, Sigma Chemicals, St. Louis, MO, USA or Microsep, Pretoria, South Africa.

\subsection{Sampling and Sample Preparation}

A total of 100 maize samples were collected from randomly selected small-scale farmers (markets) and commercial farmers (silos) in the North West Province of South Africa from April to August 2013. Fifty maize samples were collected from each of the smallscale farmers and commercial farmers, respectively. In total, $1 \mathrm{~kg}$ of each of the samples was collected in sterile plastic bags carefully labeled and conveyed to the laboratory. Each of the samples was thoroughly mixed and milled using a sterile high speed laboratory blender (IKA M20, Merck, Germany) and packaged in sealed, sterile plastic bags to avoid contamination. Samples were stored prior to analysis at minus $4{ }^{\circ} \mathrm{C}$ in the freezer.

\subsection{Mycotoxin Analysis}

\subsubsection{Immuno-Affinity Column (IAC) Mycotoxin Extraction and Clean-Up}

Extraction and clean-up of mycotoxins using IAC was done following the procedure as prescribed by the manufacturer (EASI-EXTRACT®rBiopharm, Darmstadt, Germany). The principle of this procedure is based on monoclonal antibody technology, which makes the test highly specific to toxins of interest. Apart from being specific, the test is also sensitive, rapid, and simple to perform. However, the use of this technology is constrained by cost $[16,17]$. Since different mycotoxins are involved, different solvents were used for the procedure, including methanol: water (80:20), acetonitrile: water (75:25 v/v), and acetonitrile: methanol: water $(25: 25: 50 v / v / v)$. The extracts were applied to the columns, and the mycotoxins acted as antigens binding to the antibodies present in the column. The mycotoxins were then eluted with HPLC grade methanol passed through the column while concentration of the different mycotoxins was determined using the HPLC apparatus. 


\subsubsection{Thin Layer Chromatography (TLC)}

Thin layer chromatography (TLC) using silica gel TLC plates (St Louis, MO, USA), was performed as a preliminary screening method to determine the presence of mycotoxins in maize samples prior to analysis by advanced instrumentation (HPLC).

Mycotoxin (aflatoxins (AF), fumonisin B (FB), zearalenone (ZEA), and ochratoxin A (OTA)) analysis on TLC was performed using the two dimensional technique [18], which involved the use of an aluminum-backed $20 \mathrm{~cm}$ by $20 \mathrm{~cm}$ silica gel TLC plate. The dried extracts were re-dissolved with $200 \mu \mathrm{L}$ of methanol, and $20 \mu \mathrm{L}$ was spotted on a $20 \mathrm{~mm} \times 20 \mathrm{~mm}$ silica gel TLC plate. Plates were run in solvent depending on the mycotoxin of interest, FB (BWA), ZEA (DA), AF, and OTA (DEI and TEF) (Table 1). The plates were cooled and inserted into the second mobile phase for the second run at the right angle to the first run. The developed plates for AF and OTA were viewed under UV light using Spectroline model CM-10A fluorescence analysis cabinet (spectronics corporation Westbury, NY, USA). TLC plates for ZEA were sprayed with dianisidine reagent without heating (cold spray), while plates for FB were derivatized by spraying with $P$-anisaldehyde reagent followed by heating at $120{ }^{\circ} \mathrm{C}$ for a few minutes before viewing. The distance covered by the compound (DC) was measured from the baseline to the spot, and the $\mathrm{R}_{\mathrm{F}}$ value for the spot was calculated as follows:

$$
\mathrm{R}_{\mathrm{F}}=\frac{\text { Distance covered by the compound }(\mathrm{DC})}{\text { Distance covered by solvent }(\mathrm{DC})} \times 100
$$

Table 1. Mobile phases used for TLC analysis and reagents used as derivatizing agents.

\begin{tabular}{|c|c|c|c|c|}
\hline Mycotoxins Analyzed & Aflatoxins & Fumonisins & Ochratoxin A & Zearalenone \\
\hline $\begin{array}{l}\text { Mobile phase: } \\
\text { First run }\end{array}$ & $\begin{array}{l}\text { Dichloromethane/ } \\
\text { Ethyl-acetate/ } \\
\text { Propan-2-ol (DEP) } \\
(90: 5: 5 v / v / v)\end{array}$ & $\begin{array}{c}\text { Butanol/Water/ } \\
\text { Acetic acid (BWA) } \\
(12: 5: 3 v / v / v)\end{array}$ & $\begin{array}{l}\text { Dichloromethane/ } \\
\text { Ethyl-acetate/ } \\
\text { Propan-2-ol (DEP) } \\
(90: 5: 5 v / v / v)\end{array}$ & $\begin{array}{l}\text { Dichloromethane/ } \\
\text { Acetone (DA) } \\
(90 / 10 v / v)\end{array}$ \\
\hline $\begin{array}{l}\text { Mobile phase: } \\
\text { Second run }\end{array}$ & $\begin{array}{c}\text { Toluene/ } \\
\text { Ethyl-acetate/ } \\
\text { Formic acid (TEF) } \\
(6: 3: 1 v / v / v)\end{array}$ & $\begin{array}{c}\text { Butanol/Water/ } \\
\text { Acetic acid (BWA) } \\
(12: 5: 3 v / v / v)\end{array}$ & $\begin{array}{c}\text { Toluene/ } \\
\text { Ethyl-acetate/ } \\
\text { Formic acid (TEF) } \\
(6: 3: 1 v / v / v)\end{array}$ & $\begin{array}{l}\text { Dichloromethane/ } \\
\text { Acetone (DA) } \\
(90 / 10 v / v)\end{array}$ \\
\hline Derivatizing reagent & Not applicable & Anisaldehyde solution & Not applicable & $\begin{array}{l}\text { Diazotized benzidine } \\
\text { (Dianisidine) }\end{array}$ \\
\hline
\end{tabular}

Anisaldehyde solution-70 $\mathrm{mL}$ of methanol and $5 \mathrm{~mL}$ of concentrated sulphuric acid were mixed and allowed to cool. The solution was then mixed with $10 \mathrm{~mL}$ of glacial acetic acid and $0.5 \mathrm{~mL} P$-anisaldehyde.

The retardation factor $\left(R_{F}\right)$ values were calculated per mycotoxin analyzed [19]. The retardation factor $\left(R_{F}\right)$ values and the fluorescing color of spots produced by sample extracts were compared to those of standard mycotoxins to assist in the identification of mycotoxins present.

Diazotized benzidine (Dianisidine) $-0.5 \mathrm{~g}$ of dianisidine was dissolved in $20 \mathrm{~mL}$ distilled water containing $1.5 \mathrm{~mL}$ concentrated hydrochloric acid $(\mathrm{HCl})$ and made up to $100 \mathrm{~mL}$ with distilled water. Equal volume was added to $10 \%$ sodium nitrite solution mixed and cooled to $5^{\circ} \mathrm{C}$.

\subsubsection{High Performance Liquid Chromatography (HPLC)}

The Shimadzu Prominence UFLC Liquid chromatography system (Kyoto, Japan) was used in this study. Each of the extracts from the IAC were dissolved in $500 \mu \mathrm{L}$ of HPLC grade acetonitrile. Extracts for fumonisin B analysis were dissolved in $500 \mu \mathrm{L}$ of HPLC grade methanol and according to the method prescribed by Shepherd et al. [13]. An aliquot $(25 \mu \mathrm{L})$ was derivatized with $(250 \mu \mathrm{L})$ of O-phthaldialdehyde solution (OPA from Sigma) and injected into the HPLC system within minutes due to the instability of OPA, as outlined in Table 2. The derivatized analogues can become highly unstable within a short time and rapidly break down into non-fluorescent substances. Samples were run at a 
flow rate of $1 \mathrm{~mL}$ per minute $\left(\mathrm{min}^{-1}\right)$ recording retention times. For the mobile phase, methanol/sodium dihydrogen phosphate $(80 / 20, v / v)$ was used with excitation and emission wavelengths set at 335 and $440 \mathrm{~nm}$, respectively. Aflatoxin analysis involved coupling to the detector a coring cell (CoBrA cell) (Dr Weber Consulting, Mannheim, Germany) as an electrochemical cell for the derivatization of aflatoxins at excitation and emission wavelengths of 365 and $440 \mathrm{~nm}$, respectively. In the mobile phase, methanol: acetonitrile: water $(20: 20: 60 \mathrm{v} / \mathrm{v} / \mathrm{v})$ containing $119 \mathrm{mg}$ of potassium bromide $(\mathrm{KBr})$ and $350 \mu \mathrm{L}$ of nitric acid $\left(4 \mathrm{MHNO}_{3}\right)$ was used. An analysis of ochratoxin A and zearalenone was done according to the method prescribed by Abudulkadar et al. [20] and Njobe et al. [21] with some modifications [20,21]. Ochratoxin A was determined with acetonitrile: water: acetic (50:48:02 $v / v / v)$ as mobile phase and detected at excitation and emission wavelengths of 333 and $477 \mathrm{~nm}$, respectively. In the mobile phase, acetonitrile: water (45:55 v/v) was used for the analysis of ZEA at excitation and emission wavelengths of 274 and $418 \mathrm{~nm}$, respectively. The concentration of the different mycotoxins in the samples were based on the chromatograms obtained and the mycotoxin standards used as well as the calibration curves plotted from the areas of peaks of standards and concentration of standards.

Table 2. Methods used to detect mycotoxins (AFs, FBs, OTA, and ZEA) on HPLC.

\begin{tabular}{|c|c|c|c|c|}
\hline Mycotoxins Analyzed & Aflatoxins & Fumonisins & Ochratoxin A & Zearalenone \\
\hline Extraction method & IAC & IAC & IAC & IAC \\
\hline Sample amount & $\begin{array}{l}50 \mathrm{~g} / 100 \mathrm{~mL} \\
2 \mathrm{~g} / 10 \mathrm{~mL}\end{array}$ & $\begin{array}{l}25 \mathrm{~g} / 125 \mathrm{~mL} \\
25 \mathrm{~g} / 50 \mathrm{~mL}\end{array}$ & $2 \mathrm{~g} / 15 \mathrm{~mL}$ & $\begin{array}{c}25 \mathrm{~g} / 125 \mathrm{~mL} \\
5 \mathrm{~g} / 25 \mathrm{~mL}\end{array}$ \\
\hline $\begin{array}{c}\text { Extract for } \\
\text { autosampling }\end{array}$ & $500 \mu \mathrm{L}$ & $\begin{array}{l}250 \mu \mathrm{L} \text { OPA and } \\
50 \mu \mathrm{L} \text { extract }\end{array}$ & $500 \mu \mathrm{L}$ & $500 \mu \mathrm{L}$ \\
\hline $\begin{array}{c}\text { Standards } \\
\text { concentrations }\end{array}$ & $\begin{array}{c}1.25,2.5 \\
5.0 \mathrm{ng} / \mathrm{mL}\end{array}$ & $10,20,40 \mathrm{ng} / \mathrm{mL}$ & $10,20,40 \mathrm{ng} / \mathrm{mL}$ & $5,10,20 \mu \mathrm{g} / \mathrm{mL}$ \\
\hline Injection volume & $20 \mu \mathrm{L}$ & $20 \mu \mathrm{L}$ & $20 \mu \mathrm{L}$ & $20 \mu \mathrm{L}$ \\
\hline Flow rate & $0.8 \mathrm{~mL} / \mathrm{min}$ & $1 \mathrm{~mL} / \mathrm{min}$ & $1 \mathrm{~mL} / \mathrm{min}$ & $1 \mathrm{~mL} / \mathrm{min}$ \\
\hline HPLC detector & Fluorescent & Fluorescent & Fluorescent & Fluorescent \\
\hline $\begin{array}{l}\text { Excitation/emission } \\
\text { wavelength }\end{array}$ & $365 \mathrm{~nm} / 440 \mathrm{~nm}$ & $335 \mathrm{~nm} / 440 \mathrm{~nm}$ & $336 \mathrm{~nm} / 465 \mathrm{~nm}$ & $274 \mathrm{~nm} / 418 \mathrm{~nm}$ \\
\hline
\end{tabular}

\subsubsection{Enzyme Linked Immunosorbent Assay (ELISA)}

Samples were analyzed using ELISA method as described by the Ridascreen ${ }^{(\mathrm{R})}$ (Darmstadt, Germany), manufacturer's instructions manual. The test was based on antigenantibody reaction. The wells of the microtiter strips were coated with specific antibodies against the mycotoxin of interest. Standards or the sample solutions and enzyme conjugate were added. The free mycotoxin and the enzyme-conjugated mycotoxin competed for the mycotoxin's antibody binding sites (competitive enzyme immunoassay). The unbound enzyme conjugate was then washed away in a washing step. Substrate/chromogen was added to each well and mixed gently by shaking the plate manually and incubated at room temperature $\left(20-25^{\circ} \mathrm{C}\right)$ for $15 \mathrm{~min}$ in the dark. Finally, $100 \mu \mathrm{L}$ of stop solution was added to each well and mixed gently by shaking the plate manually. The adding of the stop solution caused a color change, which was measured photometrically within $30 \mathrm{~min}$ at a wavelength of $450 \mathrm{~nm}$ using an automatic micro plate reader (Heales Model MB-580; Wellkang Ltd., London, UK). The absorption was inversely proportional to the mycotoxin concentration in the sample.

\subsection{Recovery Analysis}

This was to confirm the effectiveness of the methods used for the extraction of mycotoxins from samples. Negative maize samples or samples with known concentrations of mycotoxins were spiked in triplicates with different concentrations $(100,100,50$, and $50 \mu \mathrm{g} / \mathrm{mL}$ ), respectively, of mycotoxin standards (AFs FBs, OTA, and ZEA), mixed thor- 
oughly, and analyzed through IAC, ELISA, and HPLC following the methods described above. The following formula was used in this study:

$$
\% \text { Recovery }=\frac{\text { Amount recovered }}{\text { Amount spiked }} \times 100
$$

\subsection{Statistical Analysis}

Microsoft Excel software version 2016 was used to carry out descriptive statistics in order to determine frequency, means, standard deviation, and significant differences among the two groups of samples. Samples were analyzed in three replicates, and mean values amongst treatment groups were considered different if the probability level was $<0.05$.

\section{Results}

\subsection{Determination of Mycotoxins Using Thin Layer Chromatography (TLC)}

The retardation factor $\left(\mathrm{R}_{\mathrm{F}}\right)$ values and the fluorescing color of spots produced by sample extracts were compared to those of standard mycotoxins to assist in the identification of mycotoxins present. Results obtained for TLC analysis (Table 3) demonstrated, to some extent, the occurrence of some of the mycotoxins-fumonisin $\mathrm{B}_{1}\left(\mathrm{FB}_{1}\right)$, ochratoxin $\mathrm{A}(\mathrm{OTA})$, and zearalenone (ZEA) - whereas aflatoxins in the sample extracts did not show on TLC plates, probably due to low concentration.

Table 3. Percentage incidence of the mycotoxins in samples as determined by thin layer chromatography.

\begin{tabular}{cc}
\hline Mycotoxins & \% Incidence \\
\hline Fumonisin $\mathrm{B}_{1}\left(\mathrm{FB}_{1}\right)$ & 21 \\
Ochratoxin A (OTA) & 13 \\
Zearalenone (ZEA) & 8 \\
Aflatoxin (AFs) & Not detected \\
\hline
\end{tabular}

\subsection{Mycotoxin Determination Using HPLC and ELISA}

The results obtained revealed that $\mathrm{FB}_{1}$ s were the most contaminant mycotoxin in smallscale and commercial maize samples with incidence rates of $100 \%$ and $98.6 \%$, respectively. In the case of aflatoxins, $\mathrm{AFB}_{1}$ had incidence rates of $38 \%$ and $37 \%$ and ranged from $0.1-4.96$ to $0.4-4.80 \mu \mathrm{g} / \mathrm{kg}$ in small-scale and commercial maize samples, respectively. Furthermore, OTA had high incidence rates of $97.8 \%$ and $93.0 \%$ and ranged from 3.6-19.44 to $1.6-9.88 \mu \mathrm{g} / \mathrm{kg}$, respectively, in small-scale and commercial maize samples, while ZEA occurred in $55 \%$ and $50 \%$ of small-scale and commercial maize samples, respectively. A summary of the results is presented in Tables 4 and 5. Mycotoxin analyses using the ELISA method showed aflatoxins to have incidence rates of $41.6 \%$ and $26.1 \%$ for small-scale and commercial maize samples, respectively. Ochratoxin A and ZEA occurred at $100 \%, 100 \%$, $77 \%$, and $59.5 \%$ for small-scale and commercial maize samples, respectively.

\subsection{Method Validation in Terms of Linearity and Recoveries}

Linearity was determined by injecting mycotoxin standards at three different concentrations into the HPLC column. Calibration curves between the different areas and concentrations of standards with respective correlation coefficients $\left(R^{2}\right)$ were used to evaluate the linearity of the HPLC method. The results showed good linearity with $\mathrm{R}^{2}$ values ranging from $0.9935-0.9999$ for the different mycotoxin standards. In terms of the recovery rates, the mean percentage of recovery ranged from $79-95 \%$ for HPLC. The detection limits for the mycotoxins on ELISA were: total aflatoxins $-1.75 \mu \mathrm{g} / \mathrm{kg}$, zearalenone $-0.75 \mu \mathrm{g} / \mathrm{kg}$, and ochratoxin $\mathrm{A}-0.5 \mu \mathrm{g} / \mathrm{kg}$ with mean recovery rates ranging from $80-98 \%$ for ELISA. 
Table 4. Summary of mycotoxin contamination in small-scale maize samples as determined by high performance liquid chromatography (HPLC).

\begin{tabular}{cccc}
\hline Mycotoxins & Positive $\%$ & Range $(\mu \mathrm{g} / \mathbf{k g})$ & Mean $(\boldsymbol{\mu g} / \mathbf{k g})$ \\
\hline $\mathrm{FB}_{1}$ & 100 & $28.8-1566.7$ & $672.5( \pm 9.103)$ \\
$\mathrm{FB}_{2}$ & 39.8 & $12.4-239.0$ & $186.4( \pm 1.031)$ \\
$\mathrm{FBs}$ & 79.5 & $12.4-1652.9$ & $906.2( \pm 20.23)$ \\
$\mathrm{AFB}_{1}$ & 38.0 & $0.10-4.96$ & $3.766( \pm 0.321)$ \\
$\mathrm{AFB}$ & 23.0 & $0.009-4.92$ & $3.062( \pm 0.025)$ \\
$\mathrm{AFG}$ & 20.5 & $0.007-1.94$ & $0.16( \pm 0.014)$ \\
$\mathrm{AFG}$ & 19.4 & $0.002-1.78$ & $0.35( \pm 0.035)$ \\
$\mathrm{AFs}$ & 26.7 & $0.080-9.34$ & $4.63( \pm 0.251)$ \\
$\mathrm{ZEA}$ & 55.5 & $0.2-51.30$ & $39.2( \pm 0.045)$ \\
$\mathrm{OTA}$ & 97.8 & $3.6-19.44$ & $8.6( \pm 0.132)$ \\
\hline
\end{tabular}

Fumonisin $\mathrm{B}_{1}, \mathrm{FB}_{2}$-fumonisin $\mathrm{B}_{2}$, FBs-total fumonisin, $\mathrm{AFB}_{1}$-aflatoxin $\mathrm{B}_{1}, \mathrm{AFB}_{2}$-aflatoxin $\mathrm{B}_{2}, \mathrm{AFG}_{1}$ aflatoxin $\mathrm{G}_{1}, \mathrm{AFG}_{2}$ —aflatoxin $\mathrm{G}_{2}$, $\mathrm{AFs}$ —total aflatoxin, $\mathrm{ZEA}$-zearalenone, OTA—ochratoxin A.

Table 5. Summary of mycotoxin contamination in commercial maize samples as determined by high performance liquid chromatography (HPLC).

\begin{tabular}{cccc}
\hline Mycotoxins & Positive $\%$ & Range $(\mu \mathbf{g} / \mathbf{k g})$ & Mean $(\boldsymbol{\mu g} / \mathbf{k g})$ \\
\hline $\mathrm{FB}_{1}$ & 98.6 & $4.8-1354.2$ & $535.6( \pm 9.103)$ \\
$\mathrm{FB}_{2}$ & 37.9 & $4.2-136.0$ & $120.0( \pm 1.031)$ \\
$\mathrm{FBs}$ & 70.5 & $4.2-1401.0$ & $703.1( \pm 20.23)$ \\
$\mathrm{AFB}_{1}$ & 37.0 & $0.4-4.8$ & $3.57( \pm 0.045)$ \\
$\mathrm{AFB}_{2}$ & 23.0 & $0.16-4.2$ & $2.95( \pm 0.025)$ \\
$\mathrm{AFG}_{1}$ & 22.7 & $0.12-1.90$ & $0.16( \pm 0.025)$ \\
$\mathrm{AFG}$ & 15.5 & $0.08-1.4$ & $0.34( \pm 0.045)$ \\
$\mathrm{AFs}$ & 25.0 & $0.32-8.6$ & $4.10( \pm 0.251)$ \\
$\mathrm{ZEA}$ & 50.0 & $0.1-36.8$ & $17.5( \pm 0.045)$ \\
$\mathrm{OTA}$ & 93.0 & $1.6-9.89$ & $5.3( \pm 0.142)$ \\
\hline
\end{tabular}

Fumonisin $\mathrm{B}_{1}, \mathrm{FB}_{2}$-fumonisin $\mathrm{B}_{2}$, FBs-total fumonisin, $\mathrm{AFB}_{1}$-aflatoxin $\mathrm{B}_{1}, \mathrm{AFB}_{2}$-aflatoxin $\mathrm{B}_{2}, \mathrm{AFG}_{1}$ aflatoxin $\mathrm{G}_{1}, \mathrm{AFG}_{2}$-aflatoxin $\mathrm{G}_{2}, \mathrm{AFs}$ 一total aflatoxin, $\mathrm{ZEA}$-zearalenone, OTA—ochratoxin $\mathrm{A}$.

\section{Discussion}

Mycotoxin contamination is considered a serious food safety issue worldwide [22], as they are known to cause various health effects on exposed humans and animals.

In this study, fumonisin $\mathrm{B}_{1}$ was the most predominant mycotoxin with incidences of $100 \%$ and $98.6 \%$, respectively, in small-scale and commercial maize samples. Contamination of maize by fumonisins was considered an important risk factor in human esophageal cancer in the former Transkei regions of South Africa [2,23]. FB 1 was also implicated in the development of neural tube defects in babies of mothers consuming fumonisincontaminated maize, especially in certain regions of South Africa, China, and Italy [24,25].

Besides fumonisins contamination in maize samples analyzed, aflatoxins were the other major mycotoxins that contaminated maize. Aflatoxins appeared to be the most important contaminants in both samples with incidences of $26.7 \%$ in small-scale samples and $25 \%$ in commercial samples with mean concentrations of $4.63 \mu \mathrm{g} / \mathrm{kg}$ in small-scale samples and $4.10 \mu \mathrm{g} / \mathrm{kg}$ in commercial samples. The levels of AFs varied between $0.080-9.34 \mu \mathrm{g} / \mathrm{kg}$ and $0.32-8.60 \mu \mathrm{g} / \mathrm{kg}$ in small-scale and commercial samples, respectively (Tables 4 and 5), though these were still within the EU acceptable limits of $10 \mu \mathrm{g} / \mathrm{kg}$ (total aflatoxin) for human consumption [26,27]. Mycotoxin exposure to young children in whom cereal grains including maize may represent an important component of their weaning diet is of particular concern, as it can interfere with their growth and development. Aflatoxin contamination, for example, represents a serious health concern and is known to suppress the immune system and cause teratogenic, mutagenic, and carcinogenic effects to humans [24]. Positive correlation between aflatoxin content of food grains and occurrence of liver enlargement in children was observed [3]. Aflatoxins were linked to reduction in the average birth weight of offspring exposed prenatally and also caused decreased vitamin A and the assimilation 
of other nutrients [28]. Chronic incidence of aflatoxin in diets is evident from the presence of aflatoxin $\mathrm{M}_{1}$ in human breast milk in Ghana, Nigeria, Sierra Leone, and Sudan as well as in umbilical cord blood samples in Ghana, Kenya, Nigeria, and Sierra Leone [29]. Epidemiological studies showed a strong connection between exposure to aflatoxins and primary liver cancer [25].

A study in Benin and Togo investigated aflatoxin exposure in children and showed that exposure to this toxic contaminant increased markedly after weaning and was associated with reduced growth [29-31]. Studies showed significant correlations between aflatoxin exposure and suppression of the immune system [29,32], which may likely increase susceptibility to infections and may cause failure of immunizations. Aflatoxins were identified as a risk factor in neonatal jaundice (NNJ), although recent epidemiological studies showed inconclusive evidence of the association between NNJ and exposure to aflatoxins [33]. It was concluded that, although South African maize is virtually free from aflatoxin contamination, improper harvest and storage practices can give rise to fungal growth and, therefore, high levels of aflatoxin [34]. On the other hand, Ncube [35] reported high levels of total aflatoxin in the Limpopo Province of South Africa.

The occurrences of ZEA were 55.5\% and 50.0\% in small-scale and commercial maize samples. Both mean concentrations were $39.2 \mu \mathrm{g} / \mathrm{kg}$ and $17.5 \mu \mathrm{g} / \mathrm{kg}$, respectively, in small-scale and commercial maize samples. Sample contamination levels ranged between $0.2-51.3 \mu \mathrm{g} / \mathrm{kg}$ and $0.1-36.8 \mu \mathrm{g} / \mathrm{kg}$ for ZEA, respectively, in small-scale and commercial maize samples. These values fell below the ZEA acceptable limits of $100 \mu \mathrm{g} / \mathrm{kg}$ in maize for human consumption [27] (E.U. 2007). Zearalenone contamination of maize samples agreed with other reports of zearalenone contamination of food commodities [36,37]. Zearalenone is known to be produced in relatively cool conditions compared to other mycotoxins, but it is likely that most grains can become contaminated with ZEA during storage, and levels that were present in the grain before harvest may increase if the grain is not sufficiently dried and stored [38]. Zearalenone occurrence in foods is generally low, as observed in many studies reviewed by Placinta et al. [4], but its significance rests in its estrogenic potential in mammals. This is also in line with the findings of this study, as there were low concentrations of ZEA in the samples.

Ochratoxin A was detected in HPLC, and $97.8 \%$ and $93.0 \%$ of samples were contaminated with OTA, respectively, in small-scale and commercial samples. Ochratoxin A levels ranged between 3.6-19.44 $\mu \mathrm{g} / \mathrm{kg}$ and $1.6-9.89 \mu \mathrm{g} / \mathrm{kg}$, respectively, in small-scale and commercial samples. The levels detected were within the tolerated limits laid down by countries, a range of 3-50 $\mu \mathrm{g} / \mathrm{kg}$ for human consumption [23]. Furthermore, few African countries have reported the occurrence of OTA in maize, although its incidence in other agricultural commodities such as rice, peanut, raisins, and cocoa seeds has been reported. In this study, a high incidence of OTA in the maize samples was observed, which agrees with the study conducted by Sangare-Tigori et al. [39]. In their study on maize from Cote $\mathrm{d}$ 'Ivoire, they reported OTA to occur in $100 \%$ of the samples. Conversely, low incidence (45\% of maize samples from DR Congo) was reported to be contaminated with OTA [40]. However, in South Africa, several studies demonstrated the occurrence of this toxin in various products. Occurrence of OTA in agricultural commodities is a health concern, as toxicological reports indicated that it is nephrotoxic, carcinogenic, teratogenic, hepatotoxic, and immunotoxic [2]. Ochratoxin A was also shown to contaminate human milk and thus can cause kidney disorders in breast-fed infants. The kidney is the primary target organ for OTA toxicity but can also damage the liver at sufficiently high concentrations [37].

The results also revealed that the methods (ELISA and HPLC) used to assess mycotoxin levels in maize samples were validated and found to be sensitive for the mycotoxins analyzed. However, the HPLC method was more specific for mycotoxin detection than the ELISA method [41,42]. When comparing the HPLC results and those of ELISA, the percentage occurrences of different mycotoxins recorded in the maize samples were found to be lower than those recorded using the ELISA method (Table 6). This revealed the sensitivity of the HPLC analytical method over the ELISA method. In this study, some of 
the samples analyzed showed higher concentrations recorded using ELISA than HPLC methods in the analysis of the mycotoxins (Tables 4 and 5). This could be attributed to crossreactivity with related substances as well as matrix dependence, which often can result in tremendous overestimation. The ELISA technique normally does not include a sample clean-up procedure such as the IAC, which gives cleaner extracts, removes interfering substances, and eases mycotoxin determination. Furthermore, extraction solvents may also affect ELISA results, as it has been observed that the use of organic solvents such as aqueous methanol could lead to co-extraction of fatty materials in samples, which may interfere with the assay. This may have contributed to higher values in ELISA, since the extraction solvent was methanol.

Table 6. Summary of mycotoxin contamination in maize samples as determined by ELISA.

\begin{tabular}{cccc}
\hline Mycotoxin & Positive $\%$ & Range $(\mu \mathrm{g} / \mathbf{k g})$ & Mean $(\mu \mathrm{g} / \mathbf{k g})$ \\
\hline AFs (ss) & 45.1 & $0.00-9.27$ & $2.56( \pm 0.15)$ \\
AFs (c) & 41.6 & $0.00-5.51$ & $0.59( \pm 0.08)$ \\
ZEA(ss) & 79.5 & $1.07-48.0$ & $41.0( \pm 1.06)$ \\
ZEA(c) & 77.0 & $0.74-38.0$ & $18.73( \pm 2.13)$ \\
OTA(ss) & 100.0 & $1.05-23.2$ & $12.8( \pm 2.07)$ \\
OTA (c) & 100.0 & $0.02-11.5$ & $5.9( \pm 1.05)$ \\
\hline
\end{tabular}

Assessing the potential health risk of consumers of maize based on South African and international regulations, acceptable limits of mycotoxins were compared with the results of the study. Presently, the only two mycotoxins considered under South African national regulations are aflatoxin in all foodstuffs and patulin in apple juice [43]. Legislation for maximum tolerable levels of Fusarium mycotoxins in maize and maize products have not been determined or entrenched in South Africa. In fact, there are no maximum limits set for Fusarium mycotoxins in South Africa [44]. Depending on maize use, maize products intended for human consumption $(1000 \mu \mathrm{g} / \mathrm{kg}), 4000 \mu \mathrm{g} / \mathrm{kg}$ for unprocessed maize and $200 \mu \mathrm{g} / \mathrm{kg}$ for maize-based foods and baby foods are the various fumonisins (total of fumonisin $\mathrm{B}_{1}$ and $\mathrm{B}_{2}$ ) limits set by the European Union (E.U.) as the maximum tolerated limit (MTL) [26,27]. Depending on maize use, regulations by the USA-FDA are set at maximum levels of $2-4 \mathrm{mg} / \mathrm{kg}$ (total of fumonisin $B_{1}, B_{2}$, and $B_{3}$ ) for human consumption [45]. The South African national regulations stipulate that no food commodity destined for human consumption may contain more than $10 \mu \mathrm{g} / \mathrm{kg}$ total aflatoxin, of which only $5 \mu \mathrm{g} / \mathrm{kg}$ may be aflatoxin $\mathrm{B}_{1}$. However, aflatoxin levels in this study were below the South African acceptable limits. Fumonisins levels, on the other hand, were within E.U. and FDA acceptable limits of 1000-4000 $\mu \mathrm{g} / \mathrm{kg}$ for human consumption.

However, ZEA levels in this study were found to be below the EU recommended limits for maize intended for direct human consumption, maize-based snacks, and maizebased breakfast cereals of $100 \mu \mathrm{g} / \mathrm{kg}$ [27]. In the case of OTA, results of the level found in this study were within the recommended limit for all products derived from unprocessed cereals, including processed cereal products and cereals intended for direct human consumption, with the exception of foodstuffs for infants and young children, which is 3-50 $\mu \mathrm{g} / \mathrm{kg}[26,46]$.

Even though relatively low levels of these mycotoxins occurred in the maize samples, the fact is that it should not be taken for granted, as low levels are associated with chronic mycotoxicosis. This is because, as stated earlier, maize is a major staple food in South Africa consumed on a daily basis and in different forms. Moreover, the estimated daily intake of maize in South Africa can be as high as $400 \mathrm{~g}$ per person [47]. Therefore, due to the high maize intake levels, dietary mycotoxin loads can also be high. Hence, chronic exposure to low levels of these mycotoxins could cause various health risks coupled with the possibility of exerting synergistic or additive effects on humans and animals owing to co-contamination of different toxins in the samples. This can induce a completely different symptomatology in animals as well as in human consumers compared to exposure to a single mycotoxin $[48,49]$. Moreover, there is a high possibility that, in addition to 
the mycotoxins analyzed in this study, there could be other mycotoxins present. Such mycotoxins, referred to as "masked mycotoxins", are those which have undergone some chemical transformations and, as a result, can escape detection by routine mycotoxins analysis. These sets of mycotoxins, in essence, contribute to the total mycotoxins content of food and feed and pose additional potential risk for the consumer [50]. Furthermore, the high incidence of HIV/AIDS in South Africa combined with the consumption of mycotoxin contaminated maize could negatively affect the immune system of infected persons. Although commercially grown maize may contain lower levels of fumonisin $\mathrm{B}_{1}$ than home grown maize [14], the higher daily consumption of a greater part of the population would warrant lower maximum tolerable levels than those set by the European Union. Moreover, in rural areas of South Africa, food is difficult to come by, and people turn towards subsistence or small-scale farming, which can sometimes produce food with higher risks of mycotoxin contamination. According to Marasas [51], people in rural areas would rather choose to consume contaminated food than to starve [51]. Furthermore, maize contamination with mycotoxins-producing fungi has been linked to warm and dry climates, which is also the case with the North West province where the samples were collected. The temperatures range from $17^{\circ} \mathrm{C}$ to $31^{\circ} \mathrm{C}$ in the summer months and $3{ }^{\circ} \mathrm{C}$ to $21^{\circ} \mathrm{C}$ during the winter months, and total annual rainfall is about $360 \mathrm{~mm}$ with most of it falling between October and April [9]. This could contribute to the formation of the mycotoxins in the samples.

Nevertheless, several researchers analyzed and quantified mycotoxins in different parts of the country, especially fumonisins, but the novelty of this study is that there are limited reports from the North West province on the occurrence of mycotoxins on food commodities.

\section{Conclusions and Recommendations}

This study demonstrated that there is higher risk of mycotoxin exposure with consumption of small-scale maize than with the commercial maize in the North West Province of South Africa, with FBs being the highest contaminants. The HPLC method was more specific for mycotoxin detection than the ELISA technique. The HPLC results were lower than the percentages recorded using ELISA, which confirmed the sensitivity of HPLC over ELISA. This could be attributed to cross-reactivity with related substances resulting in overestimation in ELISA. Hence, the presence of mycotoxins contaminants in the samples should warrant intervention strategies in order to minimize their occurrence.

It is therefore recommended that continuous monitoring for mycotoxins production in maize is important in order to ensure food safety, thus minimizing consequences that may affect the health of consumers. This is because mycotoxins are chemically stable and tend to resist temperature, storage, and processing conditions. In addition, improved agronomic practices and post-harvest handling of maize are necessary to ensure a healthy food supply. Farmers, traders, and consumers should be educated on mycotoxins, their health hazards, and different ways to manage their occurrence. This can be done through seminars, workshops, and media announcements. There is also a need to train personnel at all levels, such as scientists, technicians, and extension workers in sampling protocols and modern methods of mycotoxin analysis. The adoption of GAP in the field and throughout the whole field to table chain coupled with the best sampling practices and the use of validated and fit-for-purpose analytical methods will go a long way in solving mycotoxin problems. This is particularly important because, unlike commercial farmers, small-scale farmers rely solely on their produce as the primary source of sustenance (food) and income, irrespective of its quality.

Author Contributions: Conceptualization, M.M. and T.I.E.; Methodology and validation, T.I.E. and M.M.; Formal analysis, T.I.E. and T.A.D.; Supervision, M.M.; Original manuscript preparation, T.I.E.; Proof reading, S.A.A. and N.N.; Final review and editing, M.M. All authors have read and agreed to the published version of the manuscript. 
Funding: This research was funded by The National Research Foundation of South Africa (NRF), grant number 116643, and APC was funded by the North-West University South Africa (NWU).

Informed Consent Statement: Not applicable.

Data Availability Statement: Data will be made available upon reasonable request.

Acknowledgments: The authors wish to acknowledge the North-West University and the National Research Foundation of South Africa (NRF) for the privilege to carry out this study and for the support towards the publication of the findings.

Conflicts of Interest: The authors declare no conflict of interest.

\section{References}

1. Bräse, S.; Encinas, A.; Keck, J.; Nising, C.F. Chemistry and biology of mycotoxins and related fungal metabolites. Chem. Rev. 2009, 109, 3903-4399. [CrossRef]

2. Bennett, J.W.; Klich, M. Mycotoxins. Clin. Microbiol. Rev. 2003, 16, 497-516. [CrossRef]

3. Ekwomadu, T.; Mwanza, M. A decade of mycotoxin research in Africa: A review. In Mycotoxins, Occurence, Toxicology and Management Strategies; Rios, C., Ed.; Nova Science Publishers Inc.: New York, NY, USA, 2015; pp. 169-213.

4. Placinta, C.; D'Mello, J.; Macdonald, A. A review of worldwide contamination of cereal grains and animal feed with Fusarium mycotoxins. Anim. Feed Sci. Technol. 1999, 78, 21-37. [CrossRef]

5. Timbrell, J.A. Introduction to Toxicology, 3rd ed.; Taylor and Francis: London, UK, 2002.

6. Basappa, S.C. Aflatoxins Formation, Analysis and Control; Alpha Science International Ltd.: Oxford, UK, 2009; pp. 66, 103-104.

7. Duvick, J. Prospects for reducing fumonisin contamination of maize through genetic modification. Environ. Health Perspect. 2001, 12, 337-342.

8. Muthomi, J.; Njenga, L.; Gathumbi, J. The Occurrence of Aflatoxins in Maize and Distribution of Mycotoxin-Producing Fungi in Eastern Kenya. Plant Pathol. J. 2009, 8, 113-119. [CrossRef]

9. Ekwomadu, T.I.; Gopane, R.E.; Mwanza, M. Occurrence of filamentous fungi in maize destined for human consumption in South Africa. Food Sci. Nutr. 2018, 25, 884-890. [CrossRef]

10. Sydenham, E.W.; Theil, P.G.; Marasas, W.F.O.; Shephard, G.S.; VanSchalkwyk, D.J.; Koch, K.R. Natural occurrence of some Fusarium mycotoxins in corn from low and high oesophageal cancer prevalence areas of the Transkei, Southern, Africa. J. Agric. Food Chem. 1990, 38, 1900-1903. [CrossRef]

11. Azziz-Baumgartner, E.; Lindblade, K.; Gieseker, K.; Rogers, H.S.; Kieszak, S.; Njapau, H.; Schleicher, R.; McCoy, L.F.; Misore, A.; DeCock, K.; et al. Case control study of an acute Aflatoxicosis outbreak, Kenya, 2004. Environ. Health Perspect. 2005, 113, 1779-1783. [CrossRef] [PubMed]

12. Ncube, E.; Flett, B.; Agricultural Research Council Grain Crops Institute (ARC GCI). Maize Mycotoxin Research. 2012. Available online: http:/ / www.grainsa.co.za (accessed on 24 August 2021).

13. Shephard, G.S.; Van Der Westhuizen, L.; Gatyeni, P.M.; Somdyala, N.I.M.; Burger, H.-M.; Marasas, W.F.O. Fumonisin Mycotoxins in Traditional Xhosa Maize Beer in South Africa. J. Agric. Food Chem. 2005, 53, 9634-9637. [CrossRef]

14. Burger, H.M.; Lombard, M.J.; Shephard, G.S.; Rheeder, J.R.; van der Westhuizen, L.; Gelderblom, W.C. Dietary fumonisin exposure in a rural population of South Africa. Food Chem. Toxicol. 2010, 48, 2103-2108. [CrossRef]

15. Ekwomadu, T.I.; Dada, T.A.; Nleya, N.; Gopane, R.; Sulyok, M.; Mwanza, M. Variation of Fusarium Free, Masked, and Emerging Mycotoxin Metabolites in Maize from Agriculture Regions of South Africa. Toxins 2020, 12, 149. [CrossRef]

16. Senyuva, H.Z.; Gilbert, J. Immunoaffinity column clean-up techniques in food analysis. J. Chromatogr. B 2010, 878, 115-132. [CrossRef]

17. Razzazi-Fazeli, E.; Reiter, E. (Eds.) Sample Preparation and Clean up in Mycotoxin Analysis: Principles, Applications and Recent Developments; Woodhead Publishing: Cambridge, UK, 2011; pp. 37-70.

18. Patterson, D.S.P.; Roberts, B.A. Mycotoxins in animal feedstuffs: Sensitive thin layer chromatography detection of aflatoxin, ochratoxin A, sterigmatocystin, zearalenone and T-2 toxin. J. Assoc. Off. Anal. Chem. 1979, 62, 1265-1267. [CrossRef]

19. Dutton, M.F. Mycotoxin research in South Africa. Adv. Appl. Microbiol. 2003, 53, $23-24$.

20. Abdulkadar, A.; Al-Ali, A.A.; Al-Kildi, A.M.; Al-Jedah, J.H. Mycotoxins in food products available in Qatar. Food Control 2004, 15, 543-548. [CrossRef]

21. Njobeh, P.B.; Dutton, M.F.; Koch, S.H.; Chuturgoon, A.; Stoev, S.; Seifert, K. Contamination with storage fungi of human food from Cameroon. Int. J. Food Microbiol. 2009, 135, 193-198. [CrossRef]

22. FAO (Food and Agriculture Organization). Worldwide Regulations for Mycotoxins in Food and Feed in 2003; FAO: Rome, Italy, 2004; p. 81.

23. Peraica, M.; Radić, B.; Lucić, A.; Pavlović, M. Toxic effects of mycotoxins in humans. Bull. World Health Organ. 1999, 77, 754-766. [PubMed]

24. Bhat, R.V.; Vasanthi, S. Food Safety in Food Security and Food Trade: Mycotoxin Food Safety Risk in Developing Countries; International Food Policy Research Institute (Brief 3): Washington, WA, USA, 2003. 
25. Marasas, W.F.O.; Riley, R.T.; Hendricks, K.A.; Stevens, V.L.; Sadler, T.W.; Waes, J.G.-V.; Missmer, S.A.; Cabrera, J.; Torres, O.; Gelderblom, W.C.A.; et al. Fumonisins Disrupt Sphingolipid Metabolism, Folate Transport, and Neural Tube Development in Embryo Culture and In Vivo: A Potential Risk Factor for Human Neural Tube Defects among Populations Consuming Fumonisin-Contaminated Maize. J. Nutr. 2004, 134, 711-716. [CrossRef] [PubMed]

26. European Union. Commission Regulation (EC) No. 1881/2006 of 19 December 2006 Setting Maximum Levels for Certain Contaminants in Foodstuffs (Text with EEA Relevance). 2006. Available online: http:/ / extwprlegs1.fao.org/docs/pdf/eur68134 .pdf (accessed on 24 August 2021).

27. European Union. Commission Regulation (EC) No. 1126/2007 of 28 September 2007 Amending Regulation (EC) No. $1881 / 2006$ Setting Maximum Levels for Certain Contaminants in Foodstuffs as Regards Fusarium Toxins in Maize and Maize Products. 2007. Available online: https:/ / eur-lex.europa.eu/LexUriServ/LexUriServ.do?uri=OJ:L:2007:255:0014:0017:EN:PDF (accessed on 24 August 2021).

28. Cardwell, K.F. Mycotoxin in Foods-Anti-Nutritional Factors; International Institute of Tropical Agricul: Cotonou, Benin, 1999.

29. Turner, P.C. The molecular epidemiology of chronic aflatoxin-driven impaired child growth. Scientifica 2013, $2013,152879$. [CrossRef]

30. Gong, Y.Y.; Egal, S.; Hounsa, A.; Turner, P.C.; Hall, A.J.; Cardwell, K.F.; Wild, C.P. Determinants of aflatoxin exposure in young children from Benin and Togo, West Africa: The critical role of weaning. Int. J. Epidemiol. 2003, 32, 556-562. [CrossRef] [PubMed]

31. Gong, Y.Y.; Hounsa, A.; Egal, S.; Turner, P.C.; Sutcliffe, A.E.; Hall, A.J.; Cardwell, K.; Wild, C.P. Postweaning Exposure to Aflatoxin Results in Impaired Child Growth: A Longitudinal Study in Benin, West Africa. Environ. Health Perspect. 2004, 112, 1334-1338. [CrossRef]

32. Jiang, Y.; Jolly, P.E.; Ellis, W.O.; Wang, J.-S.; Phillips, T.D.; Williams, J.H. Aflatoxin B1 albumin adduct levels and cellular immune status in Ghanaians. Int. Immunol. 2005, 17, 807-814. [CrossRef] [PubMed]

33. Galal, N.; Gamal El-Din, R.M.; Arafa, A.; Mohamad, I.M.; Abdel-Wahhab, M.A. Aflatoxin levels in Egyptian neonates with unexplainable neonatal jaundice: Morbidity and correlation to maternal assays in breast milk. Egypt. J. Neonatol. 2006, 7, 161-169.

34. Shephard, G.S. Aflatoxin and food safety: Recent African perspectives. In Aflatoxin and Food Safety; Abbas, H.K., Ed.; CRC Press, Taylor and Francis Group: Boca Raton, FL, USA, 2005; pp. 15-17.

35. Ncube, E. Mycotoxin Levels in Subsistence Farming Systems in South Africa. Master's Thesis, University of Stellenbosch, Stellenbosch, South Africa, 2008.

36. CAST. Potential economic costs of mycotoxins in the United States. In Mycotoxins: Risks in Plant, Animal and Human Systems; Task Force Report No. 139; Council for Agricultural Science and Technology: Ames, IA, USA, 2003; pp. $136-142$.

37. Richard, J.L. Some major mycotoxins and their mycotoxicoses-An overview. Int. J. Food Microbiol. 2007, 119, 3-10. [CrossRef] [PubMed]

38. Krska, R.; Richard, J.L.; Schuhmacher, R.; Slate, A.B.; Whitaker, T.B. Romer Labs Guide to Mycotoxins, 4th ed.; Binder, E.M., Krska, R., Eds.; Anytime Publishing Services: Leicestershire, UK, 2012.

39. Sangare-Tigori, B.; Dem, A.A.; Kouadio, H.J.; Betbeder, A.-M.; Dano, D.S.; Moukha, S.; Creppy, E.E. Preliminary survey of ochratoxin A in millet, maize, rice and peanuts in Côte d'Ivoire from 1998 to 2002. Hum. Exp. Toxicol. 2006, 25, 211-216. [CrossRef] [PubMed]

40. Mulunda, M.; Dzoma, B.; Nyirenda, M.; Bakunzi, F. Mycotoxins occurrence in selected staple food in main markets from Lubumbashi, DR Congo. J. Food Agric. Environ. 2013, 11, 51-54.

41. Masłowska, J.; Owczarek, A.; Kucharska, U. Determination of aflatoxins in food products by the ELISA method. Czech J. Food Sci. 2018, 19, 8-12.

42. Omar, S.S.; Haddad, M.A.; Parisi, S. Validation of HPLC and Enzyme-Linked Immunosorbent Assay (ELISA) Techniques for Detection and Quantification of Aflatoxins in Different Food Samples. Foods 2020, 9, 661. [CrossRef] [PubMed]

43. Rheeder, J.P. Guidelines on the Application of Good Agricultural Practices (GAP) and the HACCP System in Mycotoxin Prevention and Control in South Africa; South African National Health Department, Food Control Directorate: Pretoria, South Africa, 2008.

44. Fandohan, P.; Hell, K.; Marasas, W.F.O.; Wingfield, M.J. Infection of maize by Fusarium species and contamination with fumonisins in Africa. Afr. J. Biotechnol. 2003, 2, 570-579.

45. FDA (Food and Drug Administration). Fumonisin Levels in Human Foods and Animal Feeds. 2001; Final Guidance Revised on 9 November 2001. Available online: https://www.fda.gov/regulatory-information/search-fda-guidance-documents/guidanceindustry-fumonisin-levels-human-foods-and-animal-feeds (accessed on 24 August 2021).

46. European Union. Commission Regulation (EC) No. 105/2010 of 5 February 2010 Amending Regulation (EC) No. 1881/2006 Setting Maximum Levels for Certain Contaminants in Foodstuffs as Regards Ochratoxin A. 2010. Available online: https: / / eur-lex.europa.eu/LexUriServ/LexUriServ.do?uri=OJ:L:2010:035:0007:0008:EN:PDF (accessed on 24 August 2021).

47. Shephard, G.S.; Marasas, W.F.O.; Burger, H.-M.; Somdyala, N.I.M.; Rheeder, J.P.; van der Westhuizen, L.; Gatyeni, P.; van Schalkwyk, D.J. Exposure assessment for fumonisins in the former Transkei region of South Africa. Food Addit. Contam. 2007, 24, 621-629. [CrossRef]

48. Stoev, S.D.; Denev, S.; Dutton, M.F.; Njobeh, P.B.; Mosonik, J.S.; Steenkamp, P.A.; Petkov, I. Complex aetiology and pathology of mycotoxic nephropathy in South African pigs. Mycotoxin Res. 2010, 10, 31-46. [CrossRef] [PubMed] 
49. Mwanza, M. A Comparative Study of Fungi and Mycotoxin Contamination in Animal Products from Selected Rural and Urban Areas of South Africa with Particular Reference to the Impact of This on the Health of Rural Black People. Ph.D. Thesis, University of Johannesburg, Johannesburg, South Africa, 2011.

50. Di Mavungu, J.D.; de Saeger, S. Masked mycotoxins in food and feed:challenges and analytical approaches. In Determining Mycotoxins and Mycotoxigenic Fungi in Food and Feed; Saeger, S.D., Ed.; Woodhead Publishing: Cambridge, UK, 2011; pp. 385-390.

51. Marasas, W.F.O.; Gelderblom, W.C.A.; Shephard, G.S.; Vismer, H.F. Mycotoxins: A global problem. In Myctoxins: Detection Methods, Management, Public Health and Agricultural Trade; Leslie, J.F., Bandyopadhyay, R., Visconti, A., Eds.; CAB International: Wallingford, UK, 2008; p. 29. 